\title{
Multimodality imaging of indolent B cell lymphoma from diagnosis to transformation: what every radiologist should know
}

\author{
Francesco Alessandrino ${ }^{1,2^{*}}$ (D) Pamela J. DiPiro ${ }^{1,2}$, Jyothi P. Jagannathan ${ }^{1,2}$, Gosangi Babina ${ }^{1,2}$, \\ Katherine M. Krajewski ${ }^{1,2}$, Nikhil H. Ramaiya ${ }^{1,2,3}$ and Angela A. Giardino ${ }^{1,2}$
}

\begin{abstract}
Indolent B cell lymphomas are a group of lymphoid malignancies characterized by their potential to undergo histologic transformation to aggressive lymphomas. While different subtypes of indolent B cell lymphomas demonstrate specific clinical and imaging features, histologic transformation can be suspected on cross-sectional imaging when disproportionate lymph node enlargement or new focal lesions in extranodal organs are seen. On PET/CT, transformed indolent lymphoma may show new or increased nodal FDG avidity or new FDG-avid lesions in different organs. In this article, we will (1) review the imaging features of different subtypes of indolent B cell lymphomas, (2) discuss the imaging features of histologic transformation, and (3) propose a diagnostic algorithm for transformed indolent lymphoma. The purpose of this review is to familiarize radiologists with the spectrum of clinical and imaging features of indolent B cell lymphomas and to define the role of imaging in raising concern for transformation and in guiding biopsy for confirmation.
\end{abstract}

Keywords: Transformation, Follicular lymphoma, Diffuse large-cell lymphoma, Chronic lymphocytic leukemia, Nodular-lymphocyte predominant Hodgkin's lymphoma

\section{Key points}

- Indolent lymphomas can undergo histologic transformation to aggressive lymphomas

- Imaging findings of indolent and transformed lymphomas are presented

- Imaging can raise concern for transformation and guide biopsy for confirmation

- An algorithm for management of transformed indolent lymphoma is proposed
* Correspondence: falessandrino@bwh.harvard.edu

'Department of Imaging, Dana Farber Cancer Institute, Harvard Medical

School, 450 Brookline Avenue, Boston, MA 02215, USA

${ }^{2}$ Department of Radiology, Brigham and Women's Hospital, Harvard Medical

School, 75 Francis Street, Boston, MA 02115, USA

Full list of author information is available at the end of the article

\section{Introduction}

Lymphoma encompasses a heterogeneous group of lymphoid malignancies accounting for $4 \%$ of all cancers diagnosed in USA, with around 20,000 estimated deaths in 2016 [1]. First described in 1666 by Marcello Malpighi's "De viscerum structura exercitatio anatomica", lymphomas have been classified and reclassified throughout the last 50 years, with each classification reflecting the biological knowledge, the immunologic understanding, and therapeutic trends of the moment [2-6]. While the most recent classification from the World Health Organization divides lymphoid malignancies according to their immunological phenotype (into mature B cell, $\mathrm{T}$ and NK cell neoplasms, Hodgkin lymphoma (HL), post-transplant lymphoproliferative disorders (PTLD), histiocytic and dendritic cell neoplasms)), in clinical practice lymphomas are divided into indolent or low-grade lymphoma and aggressive or high-grade lymphoma [6-8]. The term "indolent lymphoma" was first introduced in 1974 to describe a 
group of lymphoid malignancies which share clinical and prognostic features of indolent clinical course and relative resistance to therapy [8].

Indolent lymphomas may undergo histologic transformation (HT), which is defined as evolution from indolent, low-grade lymphoma to aggressive, high-grade lymphoma, by means of genetic mutations with corresponding modifications in histologic architecture, clinical behavior, and prognosis of the disease $[9,10]$. Clinically, transformed indolent lymphoma (TIL) presents with new systemic or "B" symptoms (unexplained weight loss, fever, and profuse night sweating), rapid or discordant nodal growth, new involvement of extranodal sites, rising lactate dehydrogenase (LDH), and hypercalcemia $[9,11]$. Imaging has a crucial role in recognizing TIL: it helps to identify transformed lymph nodes or extranodal site involvement to guide biopsy, or can raise concern for transformation before clinically evident. In addition, imaging may allow differentiation between HT and recurrent/progressive indolent lymphoma or secondary malignancies, with change in patient management and impact on patient prognosis $[9,11-14]$. Transformation commonly occur to diffuse large B cell lymphoma (DLBCL), less commonly to other types of aggressive lymphoma, including Burkitt and $\mathrm{T}$ cell/histiocyte-rich $\mathrm{B}$ cell lymphoma (TCRBCL) $[9-11,15,16]$. Recognizing and diagnose transformation is crucial since prognosis and management of indolent lymphoma and its transformed counterpart highly differs. While follicular lymphoma (FL), the most common indolent lymphoma, shows median survival of 14 years, after transformation survival drops to $1-2$ years $[9,11,17]$. In addition, while treatment and follow up care of indolent lymphoma is based on the stage and subtype of disease, treatment and surveillance of transformed indolent lymphoma (TIL) is individualized, as currently there are no randomized studies in the modern era to guide practice $[11,12]$.

In this paper, after a brief introduction on indolent lymphomas, we will present the clinical and imaging features of most common subtypes of indolent lymphomas, we will discuss the imaging features of HT for the different subtypes of indolent lymphoma and its differential diagnosis, and eventually we will propose a imaging algorithm for diagnosis and management of TIL, so to provide the radiologist with the appropriate clinical tools to recognize indolent lymphoma from diagnosis to transformation.

\section{Indolent lymphoma: general considerations}

Indolent lymphomas are characterized by a long course of disease, with death occurring years after diagnosis [18]. Diagnosis is made through excisional-or core-needle when not feasible-biopsy of the lymph node or extra nodal tissue involved, and based on morphologic, immunophenotypic, and genetic data [6]. Subsequently, patients should undergo clinical, laboratory, imaging evaluation including PET-CT or CT to stage the disease according to the modified Ann Arbor staging system based on lymph node involvement and the presence of B symptoms in case of HL [19]. Once diagnosis and staging has been defined, the first step in management is to decide when to start therapy, and eventually which therapy regimen is appropriate [20]. Prognostic scores may also aid in decision, including the Follicular Lymphoma International Prognostic Index (FLIPI) score, which is based on patient's stage, clinical and laboratory findings, and predicts overall survival rate in patients with FL $[18,21]$. As a general rule, watchful waiting is advisable in asymptomatic patients with low-grade disease, although rituximab only has been proposed by some authors, with only limited increase in progression-free survival [22]. In limited stage disease, radiation therapy is generally used and rituximab-added chemotherapeutic regimens for more advanced stage or high-grade disease. Hematopoietic stem cell or bone marrow transplant is reserved in selected cases [10, 23]. Once decision on therapy has been made, follow up care should be set and varies according to lymphoma subtype and likelihood of progression, relapse, or transformation [11].

After a variable number of years of follow-up, generally with transient and incomplete response to therapy, death may occur due to disease progression, histologic transformation, or for unrelated causes $[1,18,22]$.

Management and treatment of the first two events, progression and $\mathrm{HT}$, is challenging, as these events are associated with high death rates [18]. Generally, treatment is individualized, depending on patient status and prior therapies $[24,25]$. In case of TIL, the R-CHOP regimen (rituximab, cyclophosphamide, hydroxydaunorubicin, oncovin, and prednisone) is recommended in patients with no prior treatment, radiotherapy, or non R-CHOP chemotherapy regimens [11, 24]. In patients with recurrent indolent lymphoma previously treated with R-CHOP, autologous stem cell transplant has been proposed [24].

\section{Clinical and imaging features of indolent lymphoma}

The most common subtypes of indolent lymphomas undergoing HT are FL, chronic lymphocytic leukemia/ small lymphocytic lymphoma (CLL/SLL), marginal zone lymphomas (MZL), Waldenstrom macroglobulinemia/ lymphoplasmacytic lymphoma (WM/LPL), and nodular lymphocyte-predominant Hodgkin lymphoma (NLPHL) [9]. These subtypes represent the $96.5 \%$ of the indolent lymphomas [1]. Their clinical and imaging characteristics are presented in Table 1.

Mycosis fungoides, a rare indolent $\mathrm{T}$ cell lymphoma which can transform to large $\mathrm{T}$ cell lymphoma, presents mostly with cutaneous lesions, will not be reviewed in this paper $[1,26]$. 
Table 1 Clinical and imaging characteristics of B cell indolent lymphomas undergoing histologic transformation

\begin{tabular}{|c|c|c|c|c|}
\hline Subtype & Epidemiology & Clinical presentation & Imaging features & $\begin{array}{l}1 / 10 \text { year } \\
\text { risk of } \mathrm{HT}\end{array}$ \\
\hline \multirow[t]{6}{*}{$\mathrm{FL}$} & 60 years old & $\begin{array}{l}\text { Asymptomatic adenopathy } \\
\text { (waxing and waning) }\end{array}$ & $\begin{array}{l}\text { Multiple, deep non-obstructive } \\
\text { adenopathy }\end{array}$ & \multirow[t]{6}{*}{$3 \% / 30 \%$} \\
\hline & \multirow[t]{5}{*}{$M>F$} & \multirow[t]{5}{*}{$\begin{array}{l}\text { Signs of extranodal } \\
\text { involvement }\end{array}$} & $\begin{array}{l}\text { Splenomegaly or focal } \\
\text { splenic lesions }\end{array}$ & \\
\hline & & & $\begin{array}{l}\text { Extranodal involvement: organomegaly } \\
\text { or focal lesions }\end{array}$ & \\
\hline & & & Bone marrow, liver, lungs, CNS (more common) & \\
\hline & & & Thyroid, parotid, breast, testis, skin (less common) & \\
\hline & & & FDG avidity: $91-100 \%$ & \\
\hline \multirow[t]{4}{*}{ CLL/SLL } & 71 years old & Asymptomatic lymphocytosis $^{a}$ & Adenopathy, splenomegaly, hepatomegaly & \multirow{4}{*}{$\begin{array}{l}0.5-1 \% / \\
16 \%\end{array}$} \\
\hline & Increases with age & Peripheral adenopathy & Heterogeneous bone marrow infiltration (MRI) & \\
\hline & \multirow[t]{2}{*}{ Rare $<40$ years old } & Splenomegaly & Brain and meningeal enhancement (MRI) & \\
\hline & & $\begin{array}{l}\text { Anemia, bleeding, } \\
\text { infections (cytopenia) }\end{array}$ & FDG avidity: 73\% (high avidity-shorter survival) & \\
\hline MZL & \multirow[t]{9}{*}{69 years old } & & & \multirow[t]{9}{*}{$0.5 \% / 10 \%$} \\
\hline \multirow[t]{5}{*}{$\begin{array}{l}\text { MALT } \\
\text { lymphoma }\end{array}$} & & Organ specific symptoms & $\begin{array}{l}\text { Adnexa oculi: enhancing issue infiltrating } \\
\text { ocular appendages }\end{array}$ & \\
\hline & & Association: & $\begin{array}{l}\text { Lung: lung nodules, consolidations, reticulation, } \\
\text { peribronchial infiltrates }\end{array}$ & \\
\hline & & Helicobacter pylori infection & $\begin{array}{l}\text { Gastrointestinal: smooth, polipoid or } \\
\text { infiltrative lesions }\end{array}$ & \\
\hline & & Hashimoto thyroiditis & & \\
\hline & & Clamydia Psittaci infection & & \\
\hline $\begin{array}{l}\text { Splenic } \\
\text { MZL }\end{array}$ & & Splenomegaly, cytopenia & $\begin{array}{l}\text { Single or multiple focal splenic lesions } \\
\text { or splenomegaly }\end{array}$ & \\
\hline \multirow{2}{*}{$\begin{array}{l}\text { Nodal } \\
\text { MZL }\end{array}$} & & Adenopathy & Adenopathy & \\
\hline & & & FDG avidity: 49\% (Ocular)-95\% (Bronchial) & \\
\hline \multirow[t]{10}{*}{ WM/LPL } & \multirow[t]{10}{*}{60 years old } & Recurrent infections, easy bruising & Bone marrow involvement (MRI) & \multirow[t]{10}{*}{$0.5 \% / 2.4 \%$} \\
\hline & & Headache, Blurry vision & Diffuse: bones iso or hypointense to muscle & \\
\hline & & Neuropathy & $\begin{array}{l}\text { Variegated: multiple enhancing foci in } \\
\text { bone marrow }\end{array}$ & \\
\hline & & \multirow[t]{7}{*}{ Organomegaly, adenopathy } & + Fractures & \\
\hline & & & Lung, pleura, skin, liver involvement & \\
\hline & & & CNS involvement (Bing-Neel syndrome) & \\
\hline & & & $\begin{array}{l}\text { T2 hyperintense hyperenhancing } \\
\text { periventricular/subcortical foci }\end{array}$ & \\
\hline & & & Meningeal or spinal enhancement & \\
\hline & & & Adenopathy & \\
\hline & & & FDG avidity: $73 \%$ & \\
\hline \multirow[t]{2}{*}{ NLPHL } & $\begin{array}{l}\text { Bimodal (childhood-4th } \\
\text { decade) }\end{array}$ & \multirow[t]{2}{*}{ Adenopathy } & $\begin{array}{l}\text { Adenopathy, splenomegaly, } \\
\text { splenic lesions }\end{array}$ & \multirow[t]{2}{*}{$0.73 \% / 10 \%$} \\
\hline & $\begin{array}{l}\text { Rare }(500 \text { cases/year } \\
\text { in USA) }\end{array}$ & & & \\
\hline
\end{tabular}

HT histologic transformation, FL follicular lymphoma, CLL/SLL chronic lymphocytic leukemia/small lymphocytic lymphoma, MZL marginal zone lymphoma, MALT mucosa associated lymphoid tissue, WM/LPL Waldenstrom macroglobulinemia/lymphoplasmacytic lymphoma; NLPHL nodular lymphocyte-predominant Hodgkin lymphoma; CNS central nervous system

${ }^{a}$ Defined as absolute lymphocyte count greater than 5000 cells $/ \mu \mathrm{L}$ 


\section{Follicular lymphoma}

Follicular lymphoma is the most common type of indolent B cell non-Hodgkin lymphoma (NHL), originating from centroblasts and centrocytes of germinal centers of the lymph nodes, the spleen, or the bone marrow and is characterized by several genetic mutations including the BCL2 translocation [11, 27, 28]. Follicular lymphoma is graded according to the number of centroblasts present at high-power field (HPF) histologic examination, from grade 1 , with $0-5$ centroblasts per HPF, to grade 3, with more than 15 centroblasts per HPF [27]. More than $90 \%$ of the diagnosed FL are grade 1 and 2 [27].

On cross-sectional imaging, FL presents with multiple, deep, non-contiguous enlarged lymph nodes, homogeneously enhancing on CT or MR (Fig. 1) [29]. Intra-abdominal adenopathy in general does not cause gastrointestinal or genitourinary symptoms [10]. The "sandwich sign," has been described in patients with mesenteric large confluent adenopathy on both sides of mesenteric vessels, with the nodal masses representing the buns and the vessels resembling the sandwich filling, giving the appearance of a hamburger [30,31]. An increased number of lymph nodes should raise suspicion for early stage of FL. FL can present also with extranodal involvement presenting with organomegaly or focal lesions $[10,29]$. The most common extranodal sites involved are the bone marrow, liver, lungs, and central nervous system, whereas involvement of the thyroid, parotid gland, breast, testis, orbits, skin, and subcutaneous tissues is unusual. Splenic involvement can be in the form of splenomegaly and FDG-avid lesions on PET/CT, T2-hyperintense homogeneously enhancing lesions on MR or hypodense focal lesions on CT [29].

On PET/CT, FL is reported as FDG avid in $91-100 \%$ of cases, in general with low avidity, depending on the histologic grade of FL [19, 20, 32-34]. Various studies compared PET/CT with CT for FL staging, showing that in up to one third of cases, PET/CT alters the stage of $\mathrm{FL}$, with consequences in patient management [12].

\section{Chronic lymphocytic leukemia/small lymphocytic lymphoma} Chronic lymphocytic leukemia/small lymphocytic lymphoma represent a spectrum of disease ranging from a pure bone marrow and blood disease (CLL) to pure extramedullary disease (SLL), in which small mutated small lymphocytes undergo uncontrolled proliferation. When HT occurs in CLL, it is termed Richter transformation. This occurs with a $0.5-1 \%$-year rate, with $16 \%$ probability of transformation at 10 years [35].

Imaging findings of CLL/SLL include adenopathy (defined as lymph nodes with short-axis diameter > $10 \mathrm{~mm}$, or as the presence of multiple small nodes in a single region) splenomegaly, hepatomegaly, and various degrees of bone marrow infiltration (Fig. 2) [3639]. Brain parenchymal and meningeal involvement has also been reported in $4 \%$ of cases. This can be evaluated with contrast-enhanced MRI, showing variable degree of abnormal parenchymal and meningeal enhancement [40]. Regarding PET/CT, on a recent study on 526 patients with CLL, FDG avidity at diagnosis was observed on $384(73 \%)$ cases, with high avidity in $120(23 \%)$ cases. In this study, high FDG avidity was associated with shorter survival [41].

\section{Marginal zone lymphoma}

Marginal zone lymphoma represents a subset of lymphoma arising from the marginal zone of the secondary follicle [42]. According to the site of involvement, MZL has been classified in mucosa-associated lymphoid tissue (MALT) lymphoma, the most common subtype, splenic lymphoma, and nodal lymphoma [4, 43]. Histologic transformation occurs with a $0.5 \%$-year rate, with $10 \%$ probability of transformation at 10 years [44].

Regarding imaging features, these depend on the location and subtype of MZL. MALT lymphoma of the
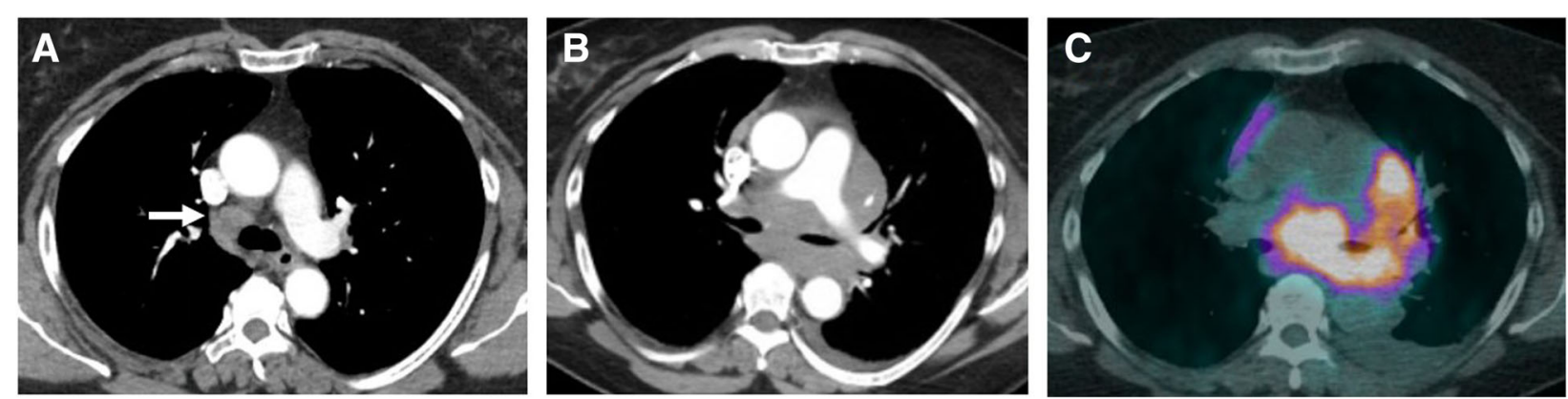

Fig. 1 A 60-year-old woman with grade I follicular lymphoma on rituxan, with new onset shortness of breath and atrial fibrillation. a Axial CT image of the chest acquired during arterial phase 1 year before onset of new symptoms shows mildly prominent mediastinal lymph nodes (arrow). b Axial CT image acquired during arterial phase at time of symptoms shows a large amorphous mediastinal mass surrounding the distal trachea and the pulmonary artery. c Axial PET/CT fused image of the chest acquired at time of symptoms shows avid FDG uptake of the mass, with SUVmax 20.1. The lesion was biopsied and showed grade III follicular lymphoma 


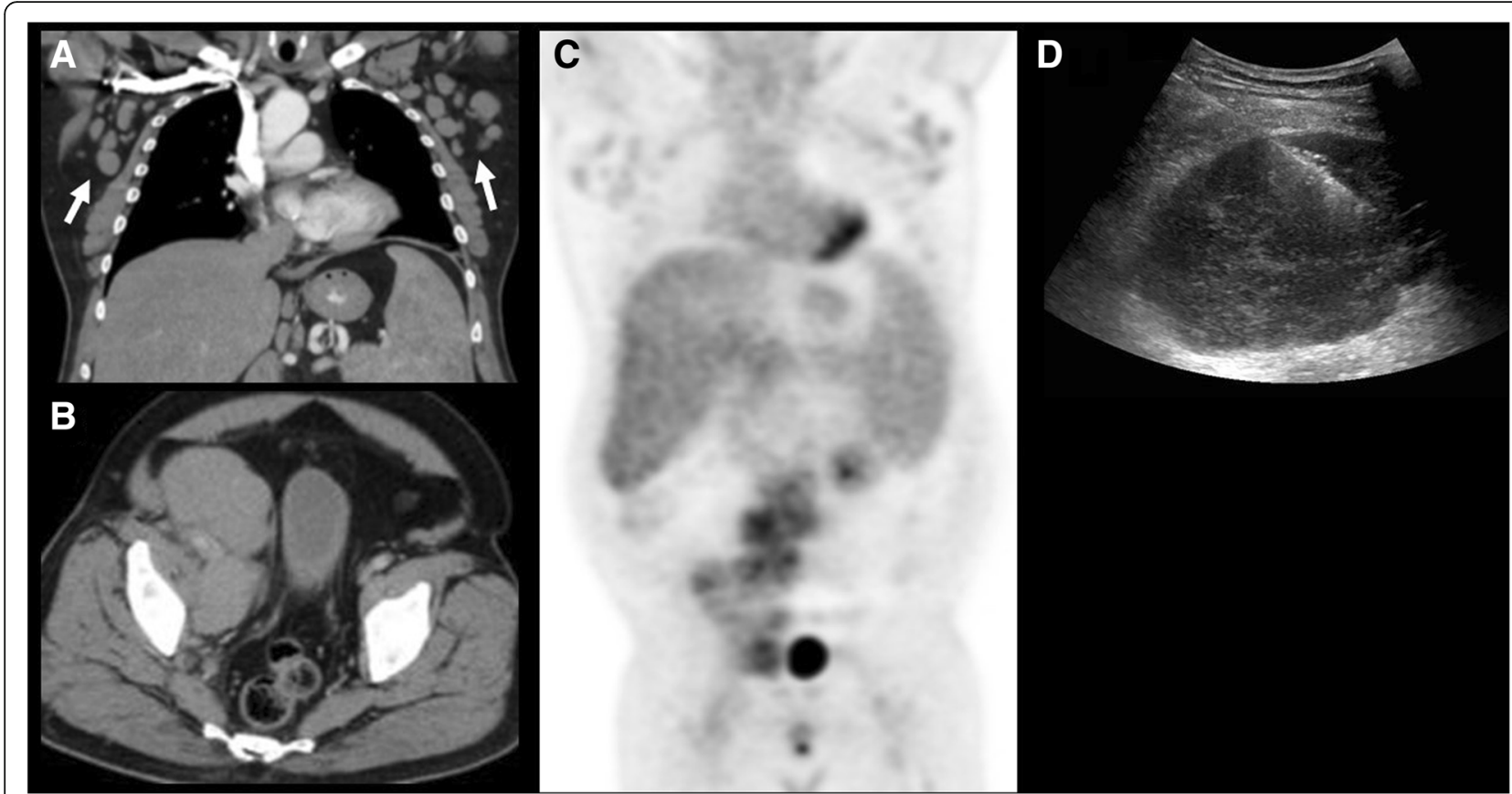

Fig. 2 A 59-year-old man with chronic lymphocytic leukemia presenting with new onset night sweats, fatigue and left upper quadrant pain. a Coronal reconstructed and axial (b) CT images acquired during portal venous phase at the time of symptoms shows mildly enlarged axillary lymph nodes (arrows) and right pelvic adenopathy. c PET image demonstrated FDG-avidity of the pelvic lymph node. d Ultrasound guided biopsy of the right pelvic adenopathy demonstrated histologic transformation to EBV-positive Hodgkin lymphoma

ocular appendages (adnexa oculi) shows homogeneously enhancing T2-hyperintense or hypoattenuating soft tissue infiltrating the adnexa on CT or MRI. MALT lymphoma of the lung shows nodules, reticulations, consolidations, and peribronchial infiltrates [43, 45]. Imaging findings of gastrointestinal tract MALT lymphoma include smooth polypoid or infiltrative lesions, with rare gastrointestinal obstruction (Fig. 3) [45]. Splenic MZL demonstrates variable spleen involvement in the form of single or multiple focal lesions, splenomegaly, or miliary lesions (smaller than $0.5 \mathrm{~cm}$ ) [46]. Sensitivity of PET/CT for MZL diagnosis ranges from 49 to $95 \%$, depending on MZL subtype

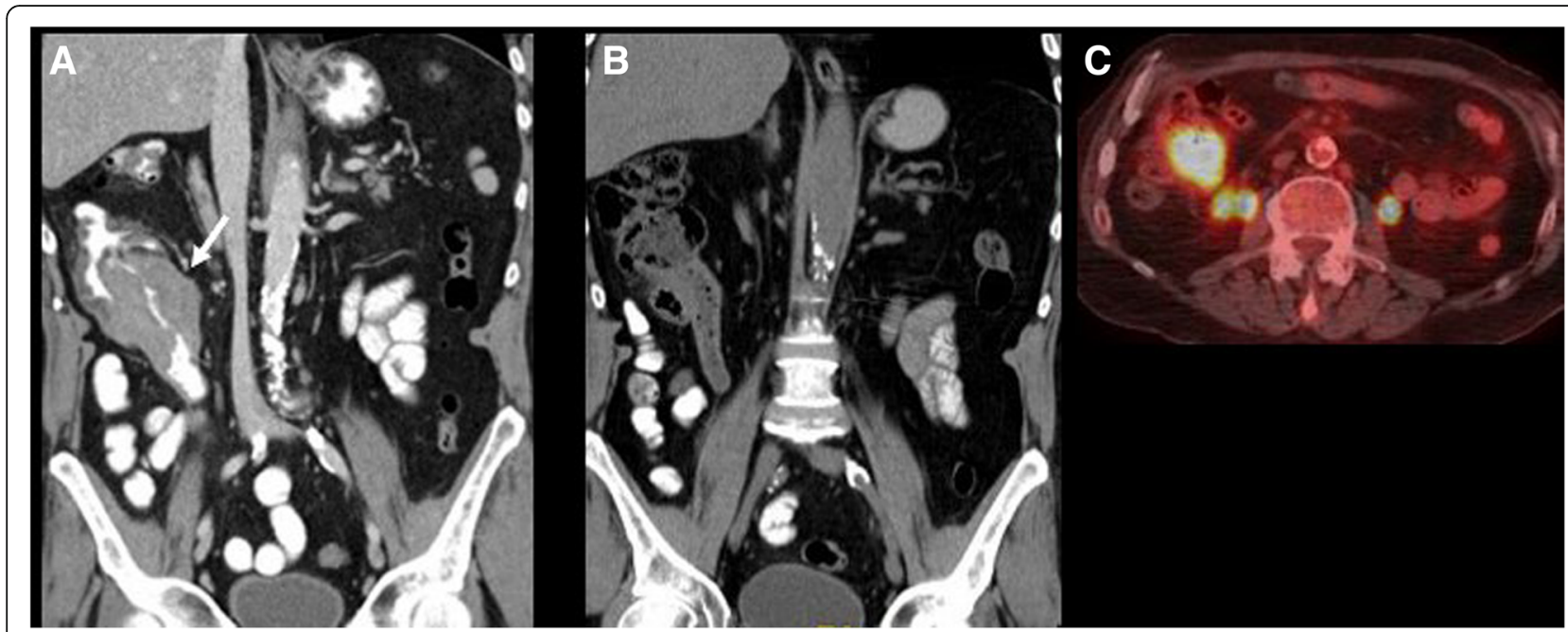

Fig. 3 A 65-year-old man with history of MALT lymphoma treated with rituximab with new onset fever and fatigue. a Coronal reconstructed CT image acquired during portal venous phase at time of diagnosis shows a large mass at the ascending colon (arrow). Biopsy of the mass demonstrated MALT lymphoma. b Coronal reconstructed CT image after 6 months of treatment shows resolution of the mass. c PET/CT axial fused image at new onset of symptoms shows intense focal FDG uptake in the region of the ileocecal valve with SUVmax 15.9. Biopsy of the mass showed histologic transformation to diffuse large B cell lymphoma 
and localization. A recent meta-analysis showed pooled sensitivity of PET/CT of $49 \%$ for diagnosis of ocular and 95\% for diagnosis of bronchial MALT lymphoma [47].

\section{Waldenstrom macroglobulinemia/lymphoplasmocytic lymphoma}

Waldenstrom macroglobulinemia/lymphoplasmocytic ly mphoma (WM/LPL) is a B cell neoplasm in which malignant lymphocytes share morphologic characteristics with mature plasma cells [48]. When an IgM paraprotein is produced and detectable in the setting of bone marrow lymphoplasmacytic infiltration, the disease is typically referred to as WM, otherwise the disease is defined LPL [48, 49]. Histologic transformation occurs with a $0.5 \%$-year rate, with a $2.4 \%$ probability of transformation at 10 years [50].

Cross-sectional imaging findings include bone marrow involvement, adenopathy, extranodal involvement, or splenic lesions or splenomegaly (Fig. 4) [10, 51, 52]. Bone marrow abnormalities are seen on MRI in $90 \%$ of patients, according to a single-center study on 23 patients, in two forms: a diffuse or a variegated pattern [50]. In the diffuse pattern, the vertebral bones are diffusely iso- or hypointense to the adjacent paravertebral muscle, while the variegated pattern reveals innumerable tiny foci of marrow replacement scattered throughout the marrow, with various degrees of enhancement [51]. Vertebral body compression fractures can also be appreciated [51]. Extranodal sites of involvement were lungs, pleura, skin, liver, and bowel [52-54]. In addition, CNS involvement of WM (Bing-Neel syndrome) has been described in literature, with T2 hyperintense enhancing periventricular and subcortical lesions with variable diffusion restriction and associated meningeal enhancement on MRI $[55,56]$. In addition, leptomeningeal or medullary enhancement can be seen in case of optic nerve or spinal cord involvement [56]. In a study on 35 patients with WM, FDG-PET/CT positivity was seen in $77 \%$ of cases [54]. PET/CT was found to be more sensitive in assessing response to treatment when compared to CT [57].

\section{Nodular lymphocyte-predominant Hodgkin lymphoma}

Nodular lymphocyte-predominant Hodgkin lymphoma is a rare subtype of HL characterized by the presence of scattered large hystiocytic and lymphocytic cells often referred as "popcorn" cells due to the multi-lobated or folded appearance of the nucleus [58]. Its clinical behavior is similar to indolent lymphoma, with slow growth, high rate of recurrence, and possibility of transformation [59-61]. A recent study on 222 patients with NLPHL reported a $0.73 \%$-year rate of $\mathrm{HT}$, with $10 \%$ probability of transformation at 10 years [58]. An increased rate of HT has been observed in patients with advanced stage and with intra-abdominal and/or spleen involvement at diagnosis $[15,58]$.

CT reveals adenopathy, more commonly supradiaphragmatic, in particular axillary or cervical, and spleen involvement [62, 63]. MRI can be helpful in assessing bone marrow involvement [64]. PET/CT shows FDG-avidity of the spleen, bone marrow, lymph nodes with sensitivity close to $100 \%$, as reported in two studies on 31 and 35 patients $[62,63]$.

\section{Imaging features of transformation}

Histologic transformation of lymphoma can occur in lymph nodes, the spleen, or in extranodal locations [62, 65-67]. Nodal transformation can be suspected when disproportionate lymph node enlargement is noted on CT, MR, or US. Nodal enlargement can be localized to a single node; regional, when lymph nodes in a nodal station are increased in size; diffuse, when multiple nodal stations are involved (Fig. 2). In addition, transformed lymph nodes may show areas of decreased

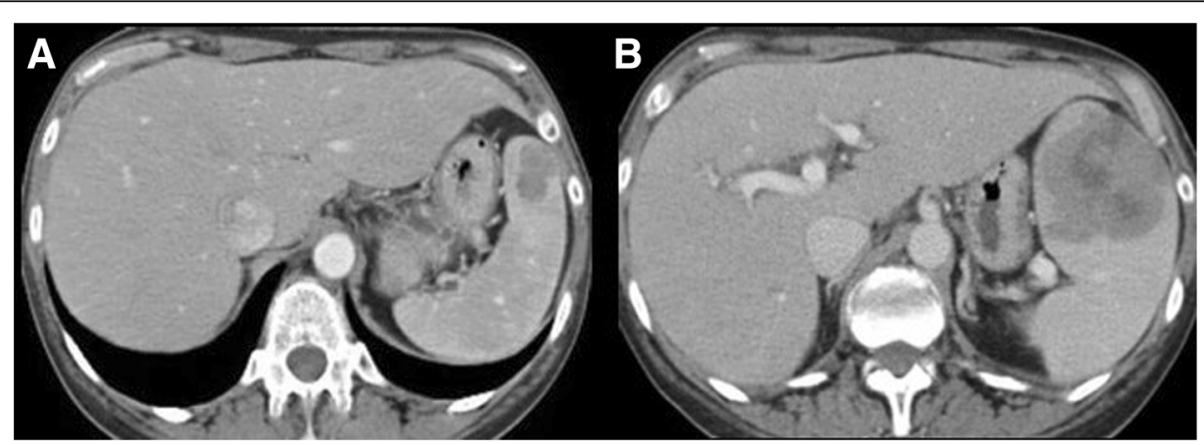

Fig. 4 A 65-year-old woman with Waldenstrom macroglobulinemia treated with chemotherapy and hematopoietic stem cell transplant and new onset fever, neutropenia, and increased LDH. a Axial CT image acquired during portal venous phase six months before the onset of new symptoms shows a hypodense lesion in the spleen. $\mathbf{b}$ Axial CT image acquired during portal venous phase at the time of symptom onset shows increased size and decreased density of the splenic lesion. Biopsy of the lesion confirmed histologic transformation to diffuse large B cell lymphoma 
density on CT, reflecting areas of necrosis (Fig. 5), a finding that is extremely uncommon in uncomplicated indolent lymphoma [65]. On PET/CT, transformed lymph nodes show higher FDG-avidity with increased SUVmax when compared to other non-transformed nodes in the same patient (Fig. 2), or in case of diffuse HT, increased FDG avidity and SUVmax compared to prior scans, with different cut-offs depending on indolent lymphoma subtypes [62, 65-69]. In cases of spleen involvement, CT shows new or increased focal hypodense lesions (Fig. 4) or new or increased splenomegaly, which is also reflected on PET/CT by diffuse increase in FDG avidity or focal FDG avid lesions in the spleen [62].

Extranodal transformation may manifest with new focal lesions in various organs, which can present as hypodense homogeneous lesions in solid organs on CT, or in case of hollow viscera, new or increased wall thickening, such as bowel or ureteral wall thickening (Fig. 6). MRI can be useful in case of suspected brain or bone marrow transformation, showing new bone marrow lesions, new areas of enhancement in the brain parenchyma, or new meningeal or cranial nerve enhancement (Fig. 7). PET/CT shows new or increased FDG avidity of the involved organs (Fig. 3). Transformation can occur in site of prior involvement or at different extranodal sites (Fig. 3).

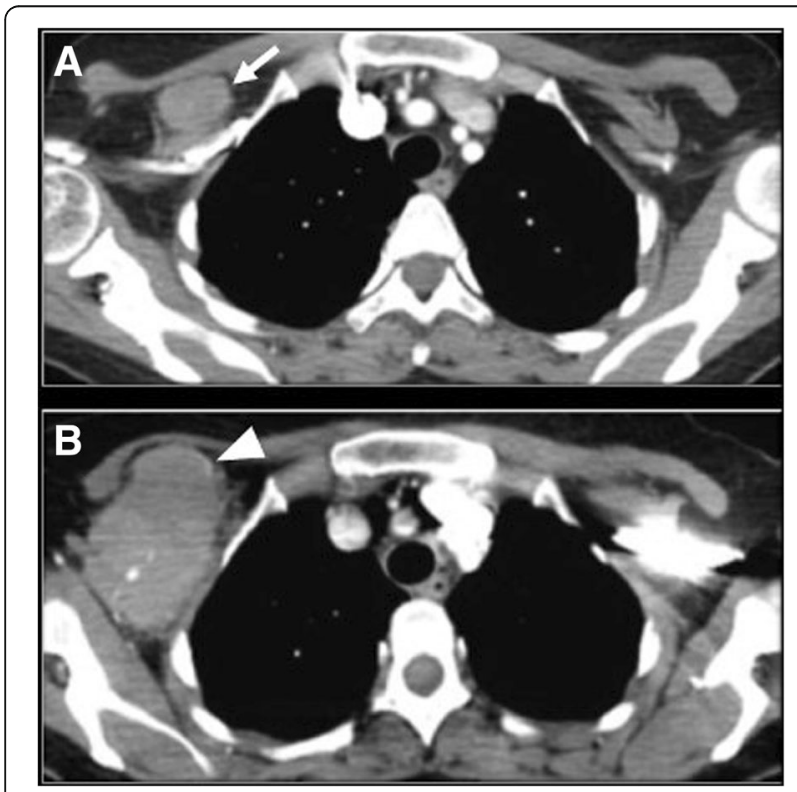

Fig. 5 A 48-year-old woman with grade I follicular lymphoma treated with rituximab and increased LDH and right arm swelling. a Axial CT image acquired during portal venous phase 6 months before the onset of new symptoms shows a right retropectoral adenopathy (arrow). b Axial CT image acquired during portal venous phase at the time of increased LDH shows increased size and areas of decreased density of the retropectoral adenopathy (arrowhead). Biopsy of the lesion shows histologic transformation to diffuse large B cell lymphoma, with areas of necrosis
In addition, it is worth mentioning that since indolent lymphomas are composed of multiple subpopulations with distinct mutations, multiple transformations can occur in the same patient with low-grade disease, sometimes either simultaneously or sequentially [11].

Regarding different types of TIL, most studies focus on FL, showing that in patients with FL and clinical signs of HT, PET/CT has proven useful to identify transformed lymph nodes in patients with clinical signs and symptoms of HT, with SUVmax of transformed lymph nodes significantly higher than for nontransformed lymph nodes [16, 66]. Due to high variability of SUV measurements and PET/CT acquisitions, the standard deviation of SUVmax is high, which renders it difficult to define a threshold for HT [68]. In addition, overreliance on SUV in asymptomatic or low-risk FL may expose patients to unnecessary biopsies and treatment, since the overall prevalence of HT (and consequently the positive predictive value of PET/CT) is low in the absence of clinical symptoms of transformation [12, 13, 24]. However, a study on 38 transformed NHL, 23 of which were FL, showed that a SUVmax of 14 had a positive predictive value of $93.9 \%$ and a negative predictive value of $95.9 \%$ [66]. A study on 90 patients with CLL showed a significantly higher median SUVmax in patients with Richter syndrome, with different values if patients transformed to DLBCL or HL. Median SUVmax in patients with DLBCL was 14.6 in cases with DLBCL and 7 in cases with HL. Extranodal involvement was observed in 5 of 17 transformed cases, with splenic, gastric, skin, and tonsil lesions [69]. Regarding MZL, a study on 167 patients with MALT lymphoma treated with radiotherapy showed transformation in 7 cases (4\%), in 5 cases at extranodal sites. In all cases, transformation occurred in sites different from the site of presentation [70]. In a study on 35 patients with WM/LPL, extranodal transformation was seen on PET/CT as a FDG-avid lesion in the bowel in 1 patient [54]. A small study compared 6 patients with NLPHL with its transformed counterpart, the TCRBCL showing that the average SUVmax was 6.9 in NLPHL and 16.6 in TCRBCL [71].

\section{Differential diagnosis \\ Progression}

Differentiating progression of indolent lymphoma from TIL can be challenging, especially in the case of progression from low- to high-grade indolent lymphoma, as there is wide overlap between clinical, histologic, and molecular characteristics of progressed and transformed lymphoma [72-74]. On imaging, these can be indistinguishable, with similar imaging characteristics, and histologic confirmation should be obtained to differentiate the two entities, whenever possible (Fig. 1). 


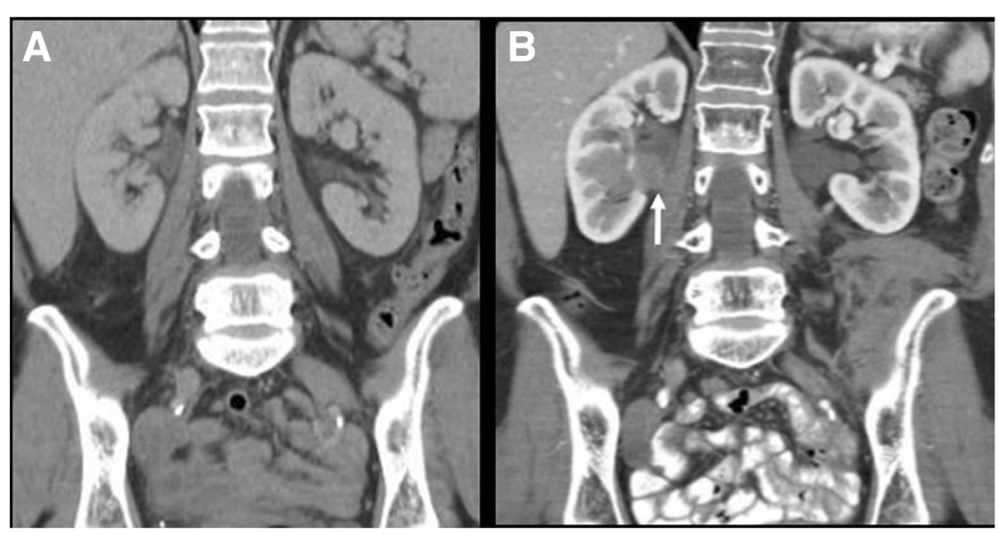

Fig. 6 A 59-year-old woman with follicular lymphoma presenting with acute abdominal pain. a Coronal reconstructed CT image acquired during portal venous phase 6 months before the onset of new symptom shows unremarkable appearance of the abdomen. $\mathbf{b}$ Axial CT image acquired during late arterial phase at the time of symptom onset shows a mass within the right renal pelvis (arrow). Biopsy of the lesion shows histologic transformation to diffuse large B cell lymphoma

\section{Recurrence}

Due to the high recurrence rate of indolent lymphomas, the possibility of recurrence of disease after initial response should be always considered when patients present with increased adenopathy or increased extranodal disease on restaging scans. To differentiate recurrence from HT, the clinical presentation can be helpful: elevated LDH, new B or systemic symptoms are most likely associated with HT [12]. On imaging, diffuse mild increase in size of multiple lymph nodes, as well as areas with only mild increase in FDG-avidity, is most likely to be associated with recurrent indolent lymphoma [29].

\section{Secondary malignancy}

Patients with lymphoma are inherently at risk of secondary tumors due to the status of immunosuppression, and patients with history of cancer can develop lymphomas. Differentiating HT from tumor progression can be difficult, especially in cases of tumors which tend to metastasize to lymph nodes. Specific imaging features of

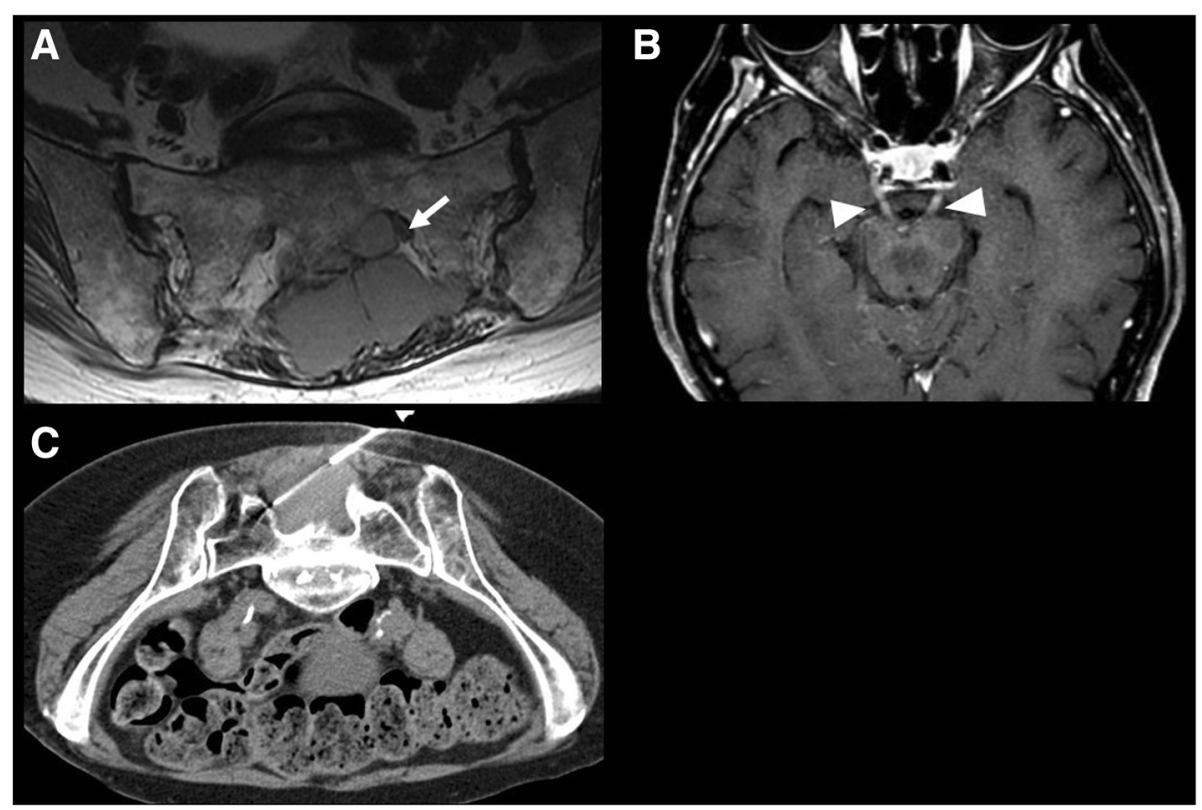

Fig. 7 A 84-year-old woman with history of nodal marginal zone lymphoma treated with cyclophosphamide, hydroxydaunorubicin, oncovin, and prednisone, presenting with new onset back pain and acute diplopia. a T2-weighted axial image showed a large mildly hyperintense mass in the sacrum extending to the left sacral ala and into the left S1 foramen (arrow). b Axial T1-weighted images of the brain showed diffuse enhancement of the bilateral III cranial nerves (arrowheads). c CT-guided biopsy of the sacral mass demonstrated histologic transformation to diffuse large B cell lymphoma 
the primary cancer, as well as concordance between primary tumor growth and nodal progression, or presence of new sites of metastasis, can be helpful to differentiate tumor progression from HT (Fig. 8).

\section{Imaging approach to transformation}

An imaging algorithm for management of suspected histologic transformation is presented in Fig. 9.

\section{Clinical scenario}

Patients with HT could present to the radiologist in two ways: as asymptomatic patients undergoing surveillance for lymphoma or CLL with evidence of HT on imaging, or patients with clinical signs or symptoms suspicious for HT, including systemic signs, such as fatigue, infections or bleeding, "B" symptoms (fever, profuse night sweats, and unexplained weight loss), adenopathy or organomegaly, and increased LDH or hypercalcemia.

\section{Imaging evaluation}

Asymptomatic patients are generally imaged with CT or PET/CT. Symptomatic patients can undergo PET/CT if the primary lymphoma is known to be FDG avid; CT if the disease is not FDG avid, to evaluate imaging characteristic of nodal disease or extranodal involvement of disease or in cases of suspected emergent conditions (splenic rupture, bowel obstruction). MRI should be reserved in cases of potential extranodal involvement, such as bone marrow, liver, kidney, central nervous system, or soft tissue involvement. Ultrasound may be useful to study morphology and sonographic characteristics of superficial lymph nodes, as a first line imaging method to study focal extranodal involvement or to guide biopsy (Fig. 2). Once PET/CT has been obtained, images should be checked for presence of discrepancy in FDG avidity within the nodal groups or extranodal sites of disease, evidence of new or increased organomegaly and whenever possible, presence of decreased density of lymph nodes. On CT, US, and MR, presence of discrepant nodal enlargement, organomegaly, or morphologic and signal characteristics of HT, such as decreased lymph node density, heterogeneous echogenicity, or increased T2-hyperintensity for nodal disease, and typical imaging features, mentioned earlier in the paper, for extranodal involvement should raise suspicion for HT.

\section{Description of findings}

In every case and for every imaging modality, recurrent disease and development of secondary tumors should be ruled out, carefully evaluating the presence of concordant increase in nodal size or FDG avidity, extranodal involvement such as breast lesions and lung nodules. In addition, if HT is suspected on imaging, potential site of HT and approach for biopsy should be

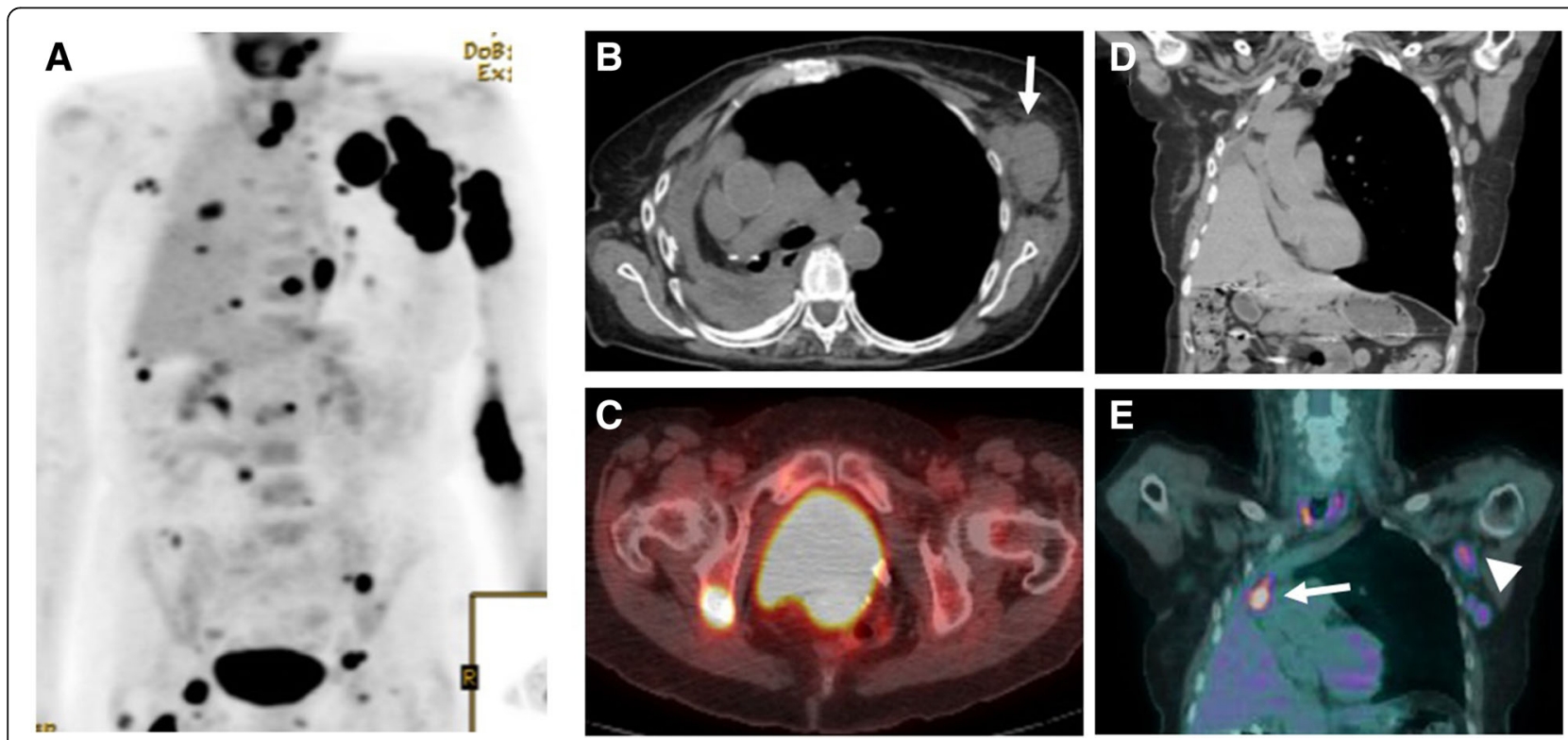

Fig. 8 A 71-year-old woman with history of non-small cell lung cancer treated with pneumonectomy and erlotinib and grade I follicular lymphoma treated with chemotherapy presenting with new left arm swelling and a left axillary mass. a Coronal MIP reconstructed PET image shows multiple FDG avid left axillary adenopathy with SUVmax of 33.4, and scattered FDG avid foci in the left arm, within the chest and abdomen. b Axial CT image showed a large axillary adenopathy (arrow). c PET-CT fused axial image shows an area of FDG uptake within the left ischium. The left axillary adenopathy and the ischiatic lesion were biopsied and were consistent with large B cell lymphoma. $\mathbf{d}$ Coronal reconstructed $\mathrm{CT}$ image acquired during portal venous phase and (e) coronal MIP reconstructed PET image acquired 6 months before the onset of symptoms showed mild FDG uptake in the primary lung mass (arrow) and left axillary lymph nodes (arrowhead), which were thought to be consistent with metastatic spread of lung cancer 


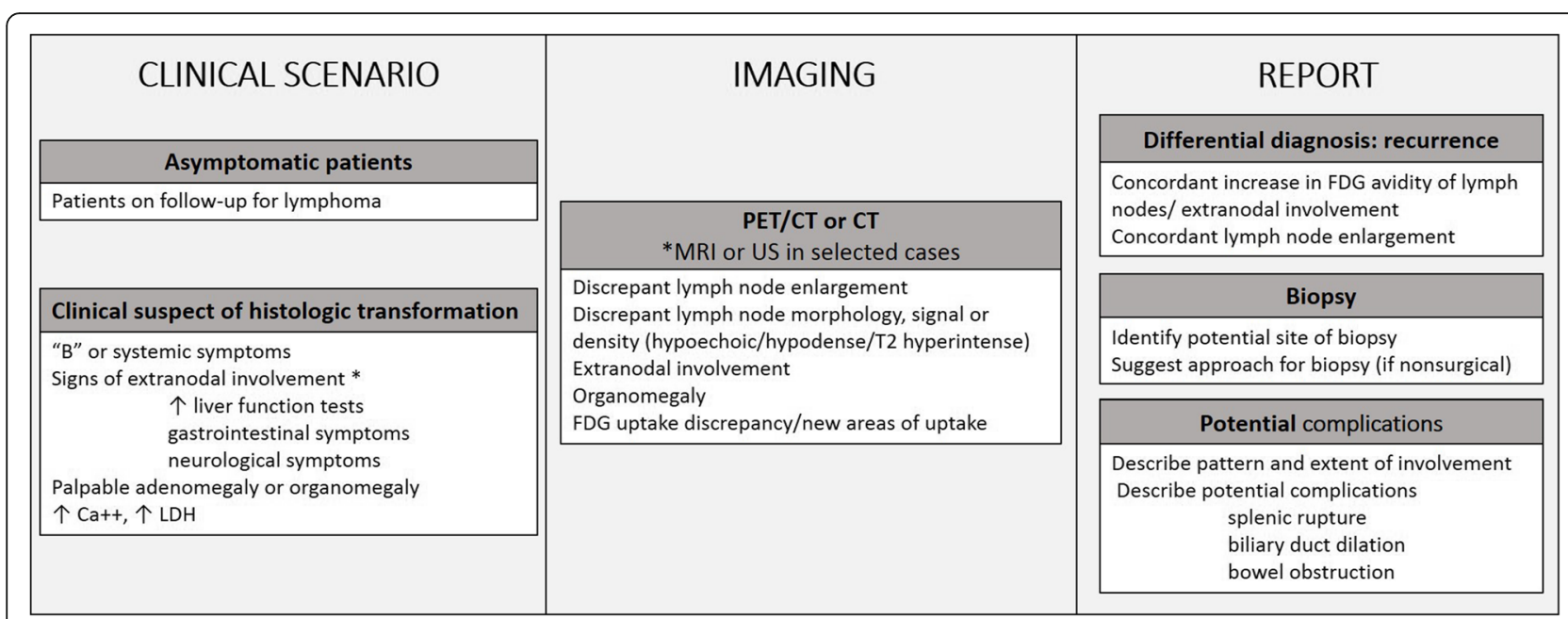

Fig. 9 Imaging algorithm for management of suspected histologic transformation

described when appropriate. Other potential complications should also be looked for and reported, including splenomegaly with impending splenic rupture, bowel obstruction, hydronephrosis, fractures, and bile duct dilation. It should be noted, however, that the likelihood of TIL in asymptomatic patients is low. Therefore, caution is necessary when raising concern of HT in these cases, as it may expose patients to unnecessary interventions and excess risks [13]. Finally, since indolent lymphomas are composed of multiple subpopulations with distinct mutations, multiple transformations can occur during the life of any patient with low-grade disease, sometimes simultaneously [11].

\section{Conclusion}

Histologic transformation represents a critical point in the natural history of indolent lymphoma, with dramatic changes in patient prognosis and treatment. Knowing the most common types of indolent lymphoma and the natural history, biology, clinical, and imaging presentation of HT will help radiologists understand their role in patient management. Radiologists should be able to recognize signs of transformation, to identify a site for potential biopsy and to recognize mimickers or complications of HT, with an impact for patient prognosis.

\section{Authors' contributions}

All authors read and approved the final manuscript.

\section{Competing interests}

The authors declare that they have no competing interests.

\section{Publisher's Note}

Springer Nature remains neutral with regard to jurisdictional claims in published maps and institutional affiliations.

\section{Author details}

'Department of Imaging, Dana Farber Cancer Institute, Harvard Medical School, 450 Brookline Avenue, Boston, MA 02215, USA. ²Department of
Radiology, Brigham and Women's Hospital, Harvard Medical School, 75 Francis Street, Boston, MA 02115, USA. ${ }^{3}$ Department of Radiology, UH Cleveland Medical Center, Case Western Reserve University, 11100 Euclid Ave, Cleveland, $\mathrm{OH}$ 44106, USA.

Received: 10 September 2018 Accepted: 14 November 2018 Published online: 22 February 2019

\section{References}

1. Teras LR, DeSantis CE, Cerhan JR, Morton LM, Jemal A, Flowers CR (2016) 2016 US lymphoid malignancy statistics by World Health Organization subtypes. CA Cancer J Clin. https://doi.org/10.3322/caac.21357

2. Malpighi M (1666) Chapter IV. In: De viscerum structura exercitatio anatomica. De Liene: 101, Bonn

3. (1982) National Cancer Institute sponsored study of classifications of nonHodgkin's lymphomas: summary and description of a working formulation for clinical usage. The Non-Hodgkin's Lymphoma Pathologic Classification Project. Cancer 49:2112-2135

4. Harris NL, Jaffe ES, Stein H et al (1994) A revised European-American classification of lymphoid neoplasms: a proposal from the international lymphoma study group. Blood 84:1361-1392

5. Sheehan WW, Rappaport H (1970) Morphological criteria in the classification of the malignant lymphomas. Proc Natl Cancer Conf 6:59-71

6. Swerdlow SH, Campo E, Pileri SA et al (2016) The 2016 revision of the World Health Organization classification of lymphoid neoplasms. Blood 127(20): 2375-2390

7. Hernández J, Krueger JE, Glatstein E (1997) Classification of non-Hodgkin's lymphoma: a proposal. Oncologist 2(4):235-244

8. Stansfeld AG, Diebold J, Noel $\mathrm{H}$ et al (1988) Updated Kiel classification for lymphomas. Lancet 1(8580):292-293

9. Freedman AS (2005) Biology and management of histologic transformation of indolent lymphoma. Hematology Am Soc Hematol Educ Program 2005:314-320

10. Matasar MJ, Zelenetz AD (2008) Overview of lymphoma diagnosis and management. Radiol Clin North Am 46(2):175-198

11. Casulo C, Burack WR, Friedberg JW (2015) Transformed follicular nonHodgkin lymphoma. Blood 125(1):40-47

12. Montoto S, Davies AJ, Matthews J et al (2007) Risk and clinical implications of transformation of follicular lymphoma to diffuse large B-cell lymphoma. J Clin Oncol 25(17):2426-2433

13. Smith SD, Redman M, Dunleavy K (2015) FDG PET-CT in follicular lymphoma: a case-based evidence review. Blood 125(7):1078-1082

14. Zelenetz AD, Gordon LI, Wierda WG et al (2014) Non-Hodgkin's lymphomas, version 2.2014. J Natl Compr Canc Netw 12(6):916-946

15. Al-Mansour M, Connors JM, Gascoyne RD, Skinnider B, Savage KJ (2010) Transformation to aggressive lymphoma in nodular lymphocytepredominant Hodgkin's lymphoma. J Clin Oncol 28(5):793-799 
16. Bernstein SH, Burack WR (2009) The incidence, natural history, biology, and treatment of transformed lymphomas. Hematology Am Soc Hematol Educ Program 2009:532-541

17. Keegan TH, McClure LA, Foran JM, Clarke CA (2009) Improvements in survival after follicular lymphoma by race/ethnicity and socioeconomic status: a population-based study. J Clin Oncol 27(18):3044-3051

18. Rohatiner AZ, Lister TA (2005) The clinical course of follicular lymphoma. Best Pract Res Clin Haematol 18(1):1-10

19. Johnson SA, Kumar A, Matasar MJ, Schöder H, Rademaker J (2015) Imaging for staging and response assessment in lymphoma. Radiology 276(2):323-338

20. Cheson BD, Fisher RI, Barrington SF et al (2014) Recommendations for initial evaluation, staging, and response assessment of Hodgkin and non-Hodgkin lymphoma: the Lugano classification. J Clin Oncol 32(27):3059-3067

21. Giné E, Montoto S, Bosch F et al (2006) The follicular lymphoma international prognostic index (FLIPI) and the histological subtype are the most important factors to predict histological transformation in follicular lymphoma. Ann Oncol 17(10):1539-1545

22. Kahl BS, Yang DT (2016) Follicular lymphoma: evolving therapeutic strategies. Blood 127(17):2055-2063

23. Shankland KR, Armitage JO, Hancock BW (2012) Non-Hodgkin lymphoma. Lancet 380(9844):848-857

24. Montoto S, Fitzgibbon J (2011) Transformation of indolent B-cell lymphomas. J Clin Oncol 29(14):1827-1834

25. Gribben JG (2007) How I treat indolent lymphoma. Blood 109:4617-4626

26. Vergier B, de Muret A, Beylot-Barry M et al (2000) Transformation of mycosis fungoides: clinicopathological and prognostic features of 45 cases. French study Group of Cutaneious Lymphomas. Blood 95(7):2212-2218

27. Harris NL, Swerdlow SH, Jaffe ES et al (2008) Follicular lymphoma. In: Swerdlow SH, Campo E, Harris NL et al (eds) WHO classification of tumours of hematopoietic and lymphoma tissues, 4th edn. International Agency for Research on Cancer, Lyon, France, pp 158-166

28. Armitage JO, Weisenburger DD (1998) New approach to classifying non-Hodgkin's lymphomas: clinical features of the major histologic subtypes. Non-Hodgkin's lymphoma classification project. J Clin Oncol 16(8):2780-2795

29. Hayashi D, Lee JC, Devenney-Cakir B et al (2010) Follicular non-Hodgkin's lymphoma. Clin Radiol 65(5):408-420

30. Mueller PR, Ferrucci JT Jr, Harbin WP, Kirkpatrick RH, Simeone JF, Wittenberg $J$ (1980) Appearance of lymphomatous involvement of the mesentery by ultrasonography and body computed tomography: the "sandwich sign". Radiology 134(2):467-473

31. Medappil N, Reghukumar R (2010) Sandwich sign in mesenteric lymphoma. J Cancer Res Ther 6(3):403-404

32. Barrington SF, Mikhaeel NG, Kostakoglu $L$ et al (2014) Role of imaging in the staging and response assessment of lymphoma: consensus of the international conference on malignant lymphomas imaging working group. J Clin Oncol 32(27):3048-3058

33. Hofman MS, Hicks RJ (2011) Imaging in follicular NHL. Best Pract Res Clin Haematol 24(2):165-177

34. Chen YK, Yeh CL, Tsui CC, Liang JA, Chen JH, Kao CH (2011) F-18 FDG PET for evaluation of bone marrow involvement in non-Hodgkin lymphoma: a meta-analysis. Clin Nucl Med 36(7):553-559

35. Agbay RL, Jain N, Loghavi S, Medeiros LJ, Khoury JD (2016) Histologic transformation of chronic lymphocytic leukemia/small lymphocytic lymphoma. Am J Hematol 91(10):1036-1043

36. Lecouvet FE, Vande Berg BC, Michaux L et al (1997) Early chronic lymphocytic leukemia: prognostic value of quantitative bone marrow MR imaging findings and correlation with hematologic variables. Radiology 204(3):813-818

37. Eichhorst BF, Fischer K, Fink AM et al (2011) Limited clinical relevance of imaging techniques in the follow-up of patients with advanced chronic lymphocytic leukemia: results of a meta-analysis. Blood 117(6):1817-182

38. Gentile M, Cutrona G, Molica S et al (2016) Prospective validation of predictive value of abdominal computed tomography scan on time to first treatment in Rai 0 chronic lymphocytic leukemia patients: results of the multicenter O-CLL1-GISL study. Eur J Haematol 96(1):36-45

39. Muntañola A, Bosch F, Arguis P et al (2007) Abdominal computed tomography predicts progression in patients with Rai stage 0 chronic lymphocytic leukemia. J Clin Oncol 25(12):1576-1580

40. Strati P, Uhm JH, Kaufmann TJ et al (2016) Prevalence and characteristics of central nervous system involvement by chronic lymphocytic leukemia. Haematologica 101(4):458-465
41. Conte MJ, Bowen DA, Wiseman GA et al (2014) Use of positron emission tomography-computed tomography in the management of patients with chronic lymphocytic leukemia/small lymphocytic lymphoma. Leuk Lymphoma 55(9):2079-2084

42. Thieblemont C (2005) Clinical presentation and management of marginal zone lymphomas. Hematology Am Soc Hematol Educ Program 2005:307-313

43. Maksimovic O, Bethge WA, Pintoffl JP et al (2008) Marginal zone B-cell non-Hodgkin's lymphoma of mucosa-associated lymphoid tissue type: imaging findings. AJR Am J Roentgenol 191(3):921-930

44. Khalil MO, Morton LM, Devesa SS et al (2014) Incidence of marginal zone lymphoma in the United States, 2001-2009 with a focus on primary anatomic site. Br J Haematol 165(1):67-77

45. Hayashi D, Devenney-Cakir B, Lee JC et al (2010) Mucosa-associated lymphoid tissue lymphoma: multimodality imaging and histopathologic correlation. AJR Am J Roentgenol 195(2):W105-W117

46. Saboo SS, Krajewski KM, O'Regan KN et al (2012) Spleen in haematological malignancies: spectrum of imaging findings. Br J Radiol 85(1009):81-92

47. Treglia G, Zucca E, Sadeghi R, Cavalli F, Giovanella L, Ceriani L (2015) Detection rate of fluorine-18-fluorodeoxyglucose positron emission tomography in patients with marginal zone lymphoma of MALT type: a meta-analysis. Hematol Oncol 33(3):113-124

48. Treon SP (2015) How I treat Waldenström macroglobulinemia. Blood 126(6):721-732

49. Agbay RL, Loghavi S, Medeiros LJ, Khoury JD (2016) High-grade transformation of low-grade B-cell lymphoma: pathology and molecular pathogenesis. Am J Surg Pathol 40(1) e1-16

50. Castillo JJ, Gustine J, Meid K, Dubeau T, Hunter ZR, Treon SP (2016) Histological transformation to diffuse large B-cell lymphoma in patients with Waldenström macroglobulinemia. Am J Hematol 91(10):1032-1035

51. Moulopoulos LA, Dimopoulos MA, Varma DG et al (1993) Waldenström macroglobulinemia: MR imaging of the spine and CT of the abdomen and pelvis. Radiology 188(3):669-673

52. Amini B, Yellapragada S, Shah S, Rohren E, Vikram R (2016) State-of-the-art imaging and staging of plasma cell Dyscrasias. Radiol Clin North Am 54(3):581596

53. Walker RC, Brown TL, Jones-Jackson LB, De Blanche L, Bartel T (2012) Imaging of multiple myeloma and related plasma cell dyscrasias. J Nucl Med 53(7):1091-1101

54. Banwait R, O'Regan K, Campigotto F et al (2011) The role of 18F-FDG PET/CT imaging in Waldenstrom macroglobulinemia. Am J Hematol 86(7):567-572

55. Drappatz J, Akar S, Fisher DC, Samuels MA, Kesari S (2008) Imaging of BingNeel syndrome. Neurology 70(16):1364

56. Simon L, Fitsiori A, Lemal $R$ et al (2015) Bing-Neel syndrome, a rare complication of Waldenström macroglobulinemia: analysis of 44 cases and review of the literature. A study on behalf of the French innovative leukemia organization (FILO). Haematologica 100(12):1587-1594

57. Keraliya AR, Krajewski KM, Jagannathan JP et al (2016) Multimodality imaging of osseous involvement in haematological malignancies. $\mathrm{Br} J$ Radiol 89(1059):20150980

58. Savage KJ, Mottok A, Fanale M (2016) Nodular lymphocyte-predominant Hodgkin lymphoma. Semin Hematol 53(3):190-202

59. Smith LB (2010) Nodular lymphocyte predominant Hodgkin lymphoma: diagnostic pearls and pitfalls. Arch Pathol Lab Med 134(10):1434-1439

60. McKay P, Fielding P, Gallop-Evans E, et al (2016) Guidelines for the investigation and management of nodular lymphocyte predominant Hodgkin lymphoma. Br J Haematol 2016;172(1):32-43

61. Kenderian SS, Habermann TM, Macon WR et al (2016) Large B-cell transformation in nodular lymphocyte-predominant. Blood 127(16):1960-1966

62. Grellier JF, Vercellino L, Leblanc T et al (2014) Performance of FDG PET/CT at initial diagnosis in a rare lymphoma: nodular lymphocyte-predominant Hodgkin lymphoma. Eur J Nucl Med Mol Imaging 41(11):2023-2030

63. Ansquer C, Hervouët T, Devillers A et al (2008) 18-F FDG-PET in the staging of lymphocyte-predominant Hodgkin's disease. Haematologica 93(1):128-131

64. Zhao FX (2008) Nodular lymphocyte-predominant Hodgkin lymphoma or T-cell/Histiocyte rich large B-cell lymphoma: the problem in "Grey zone" Iymphomas. Int J Clin Exp Pathol 1:300-305

65. Giardino AA, O'Regan K, Jagannathan JP, Elco C, Ramaiya N, Lacasce A (2011) Richter's transformation of chronic lymphocytic leukemia. J Clin Oncol 29(10):e274-e276 
66. Bodet-Milin C, Kraeber-Bodéré F, Moreau P, Campion L, Dupas B, Le Gouill S (2008) Investigation of FDG-PET/CT imaging to guide biopsies in the detection of histological transformation of indolent lymphoma. Haematologica 93(3):471-472

67. Bruzzi JF, Macapinlac H, Tsimberidou AM et al (2006) Detection of Richter's transformation of chronic lymphocytic leukemia by PET/CT. J Nucl Med 47(8):1267-1273

68. Kinahan PE, Fletcher JW (2010) Positron emission tomography-computed tomography standardized uptake values in clinical practice and assessing response to therapy. Semin Ultrasound CT MR 31(6):496-505

69. Mauro FR, Chauvie S, Paoloni F et al (2015) Diagnostic and prognostic role of PET/CT in patients with chronic lymphocytic leukemia and progressive disease. Leukemia 29(6):1360-1365

70. Goda JS, Gospodarowicz M, Pintilie M et al (2010) Long-term outcome in localized extranodal mucosa-associated lymphoid tissue lymphomas treated with radiotherapy. Cancer 116(16):3815-3824

71. Barber NA, Loberiza FR Jr, Perry AM et al (2013) Does functional imaging distinguish nodular lymphocyte-predominant hodgkin lymphoma from Tcell/histiocyte-rich large B-cell lymphoma? Clin Lymphoma Myeloma Leuk 13(4):392-397

72. Biasoli I, Stamatoullas A, Meignin V et al (2010) Nodular, lymphocytepredominant Hodgkin lymphoma: a long-term study and analysis of transformation to diffuse large B-cell lymphoma in a cohort of 164 patients from the adult lymphoma study group. Cancer 116(3):631-639

73. Lin P, Mansoor A, Bueso-Ramos C, Hao S, Lai R, Medeiros LJ (2003) Diffuse large B-cell lymphoma occurring in patients with lymphoplasmacytic lymphoma/Waldenström macroglobulinemia clinicopathologic features of 12 cases. Am J Clin Pathol 120(2):246-253

74. Müller-Hermelink HK, Zettl A, Pfeifer W, Ott G (2001) Pathology of lymphoma progression. Histopathology 38:285-306

\section{Submit your manuscript to a SpringerOpen ${ }^{\circ}$ journal and benefit from:}

- Convenient online submission

- Rigorous peer review

- Open access: articles freely available online

High visibility within the field

- Retaining the copyright to your article

Submit your next manuscript at $\boldsymbol{\nabla}$ springeropen.com 